\title{
Research on determining the safe mining depth in special geological conditions of Mong Duong coal mine
}

\author{
Chung Van Pham ${ }^{1 *}$, Dac Manh Phung ${ }^{2}$, Ha Thu Thi Le ${ }^{1}$, Trong Gia Nguyen ${ }^{1}$, Trung \\ Thanh Ngo ${ }^{3}$, Thang Vu Tran ${ }^{4}$ \\ ${ }^{1}$ Hanoi University of Mining and Geology, Hanoi, Vietnam \\ 2 Vietnam Mining Science and Technology Association, Hanoi, Vietnam \\ ${ }^{3}$ Mining Geology Joint Stock Company - TKV, Hanoi, Vietnam \\ ${ }^{4}$ Institute of Mining Science and Technology, Hanoi, Vietnam
}

ARTICLE INFO

Article history:

Received 14th May 2021

Revised $14^{\text {th }}$ Aug. 2021

Accepted 09th 0 ct. 2021

Keywords:

Displacement deformation,

Exploitation of seams,

Safety depth,

Special geology.
ABSTRACT

The displacement and deformation of strata due to underground mining is one of the factors that negatively affect the safety of production activities. The strata displacement and deformation depend on many factors such as mining geological conditions, safe mining depths, and mining technologies. The determination of the safe depths is important for calculating the size of safety pillars to minimize mineral loss. To date, there have been many studies to determine safe mining depths under normal geological conditions. However, not much research has been conducted to determine safe mining depths with special geological conditions such as many folds, breaks, faults, and under water-bearing objects. This research introduces a method to determine the safe mining depths for the reservoir set in special geological conditions with folds and excavating several seams under water bodies. The proposed method employs the principle of the similar geological zone theory to calculate the safe mining depths. The method is applied to the Mong Duong coal mine, with three coal seams numbered 5, 6, and 7 with the depth of 210, 180, and $136 \mathrm{~m}$, respectively. The results of mining depths safe obtained $\mathrm{H}_{5}=$ $240 \mathrm{~m}, H_{6}=192 \mathrm{~m}, H_{7}=136 \mathrm{~m}$, respectively.

Copyright (C) 2021 Hanoi University of Mining and Geology. All rights reserved.

${ }^{*}$ Corresponding author

E - mail: phamvanchung@humg.edu.vn

DOI: 10.46326/JMES.2021.62 (5).07 


\title{
Tạp chí Khoa học Kỹ thuật Mỏ - Địa chất
}

Trang điện tử: http://tapchi.humg.edu.vn

\section{Nghiên cứu xac đinh độ sâu khai thác an toan trong điều kiện địa chất đặc biệt ở mo than Mong Dương}

\author{
Phạm Văn Chung 1* ${ }^{*}$, Phùng Mạnh Đắc ${ }^{2}$, Lê Thị Thu Hà ${ }^{1}$, Nguyễn Gia Trọng ${ }^{1}$, Ngô \\ Thành Trung ${ }^{3}$, Trần Vũ Thăng 4 \\ ${ }^{1}$ Trường Đại học Mỏ - Địa chất, Hà Nội, Việt Nam \\ ${ }^{2}$ Hội Khoa học và Công nghệ Mỏ Việt Nam, Hà Nội, Việt Nam \\ ${ }^{3}$ Công ty CP Địa chất Mỏ - TKV, Hà Nội, Việt Nam \\ 4 Viện Khoa học và Công nghệ Mỏ - Vinacomin, Hà Nội, Việt Nam
}

\begin{tabular}{|c|c|}
\hline THÔNG TIN BÀI BÁO & TÓM TẮT \\
\hline $\begin{array}{l}\text { Quá trình: } \\
\text { Nhận bài } 14 / 5 / 2021 \\
\text { Sưa xong } 14 / 8 / 2021 \\
\text { Chap nhận đăng } 10 / 9 / 2021\end{array}$ & 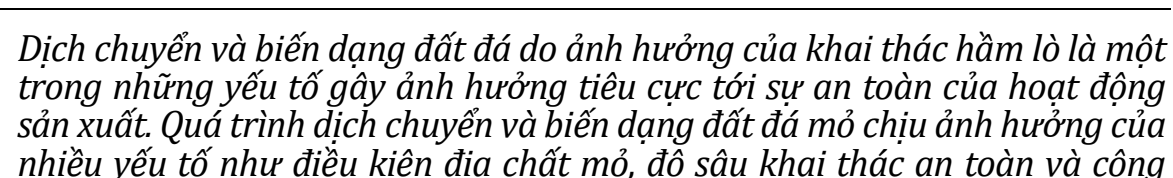 \\
\hline $\begin{array}{l}\text { Tù̀ khóa: } \\
\text { Chiều sâu an toàn, } \\
\text { Dịch chuyển biến dạng, } \\
\text { Địa chất đặc biệt, } \\
\text { Khai thác tập vỉa. }\end{array}$ & 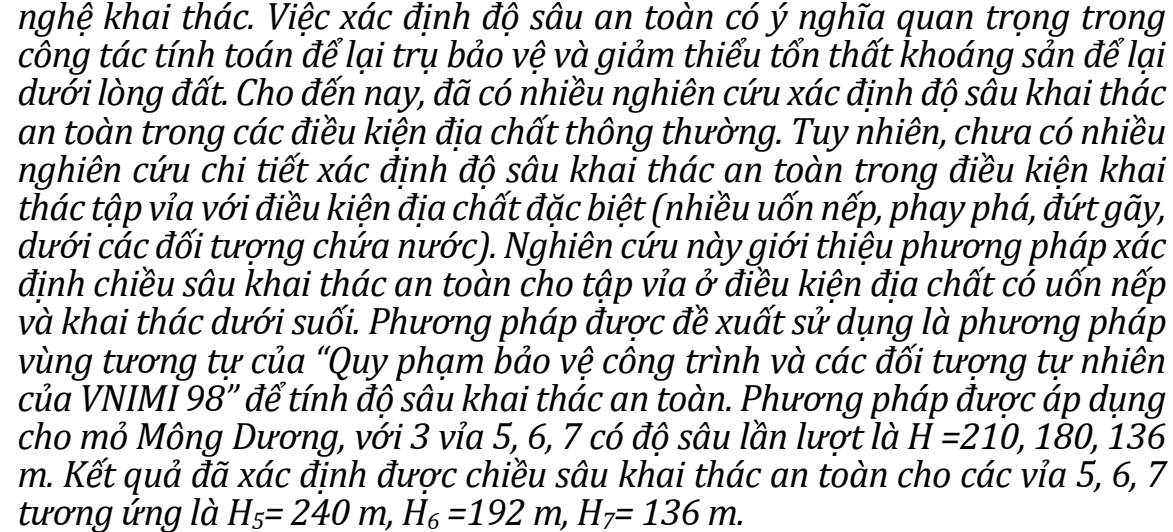 \\
\hline
\end{tabular}

(C) 2021 Trường Đại học Mỏ - Địa chất. Tất cả các quyền được bảo đảm.

\section{Mở đầu}

Mo than Mong Dương co trữ lượng công nghiệp khá lớn, phân bố trên diện tích rộng với

*Tác giả liên hệ

E - mail: phamvanchung@humg.edu.vn

DOI: 10.46326/JMES.2021.62 (5).07 nhiều tập vỉa bao gồm I12, II11, 7, 6, 5 (Phạm Văn Chung và Vương Trọng Kha, 2012). Mỏ nằm trong vùng có các yếu tố địa chất phức tạp do có nhiều hoạt động kiến tạo như đứt gãy, uốn nếp (Phạm Đại Hải và nnk., 2004), nên đã gây ra sự biến động lớn về giá trị các góc dịch chuyển và biến dạng. Đồng thời, trên bề mặt mỏ cũng tồn tại nhiều đối tượng chứa nước như: sông Mông Dương, suối Vũ Môn và 
các đầm ven biển, gây nguy cơ bục nước vào lò. Các đứt gẫy kiến tạo hình thành nên những mặt yếu trong khai trường mỏ, có thể gây ảnh hưởng lớn đến các thông số, tính chất quá trình dịch chuyển. Nếu không tính đến những ảnh hưởng này, khi khai thác tập vỉa trên, có thể xảy ra biến dạng, tập trung tại các vùng lộ vết đứt gãy, gây nguy hiểm đến các công trình trên bề mặt mỏ.

Trên thế giới có nhiều công trình nghiên cứu ảnh hưởng của khai thác hầm lò lên bề mặt. Các nghiên cứu trước đây thường tập trung theo hướng xây dựng các mô hình vật liệu tương đương (Vardoulakis I. và nnk., 1981), mô hình toán học (Agnieszka Malinowska và nnk., 2020), quan trắc thực địa (Nguyen Quoc Long, 2017). Trong thời gian gần đây, các phương pháp hiện đại như mô hình trí tuệ nhân tạo (Ambrožič Tomaž, 2003), quét laser mặt đất (Xiaoping Z., 2016), ảnh vệ tinh (Zhang, Z., 2015; Alex Hay - Man Ng., 2017; Ryszard Hejmanowski, 2019) đã được ứng dụng để xác định biến dạng bề mặt.

Tại Việt Nam, đã có một số nghiên cứu về dịch chuyển biến dạng cho khu vực Mông Dương - Khe Chàm, các nghiên cứu chủ yếu dựa trên số liệu quan trắc để xác định các giá trị biến dạng bề mặt (Phạm Văn Chung, 2019; Nguyen Quoc Long, 2019). Bên cạnh đó, một số nghiên cứu khác lại dựa trên các số liệu quan trắc để xây dựng các hàm dự báo sụt lún bề mặt (Nguyễn Quốc Long, 2020).

Dễ nhận thấy rằng, các nghiên cứu này chủ yếu cho điều kiện khai thác các vỉa than bằng và thoải, chưa đề cập tới các điều kiện về cấu trúc phức tạp của địa chất. Do vậy, cần nghiên cứu xác định chiều sâu an toàn khi khai thác tập vỉa trong điều kiện đứt gãy, uốn nếp và dưới các đối tượng chứa nước để đảm bảo khai thác thác an toàn và hiệu quả cho các mỏ hầm lò nói chung và cho mỏ Mông Dương nói riêng.

\section{2. Đặc điểm chung về địa chất - khai thác mỏ}

Mỏ than Mông Dương hiện nằm trên địa phận phường Mông Dương, cách trung tâm Thành phố Cẩm Phả, tỉnh Quảng Ninh khoảng $20 \mathrm{~km}$. Phía bắc giáp sông Mông Dương; phía nam giáp mỏ than Bắc Quảng Lợi; phía tây giáp mỏ Khe Chàm, Cao Sơn; phía đông giáp sông Mông Dương và quốc lộ 18A (Nguyễn Tam Sơn và nnk., 2005).

Địa hình mỏ than Mông Dương là vùng núi thấp đến trung bình, cao nhất +165 m (Khu trung tâm); thấp nhất -0,1 m (lòng sông Mông Dương)
Trong khu mỏ có hai suối lớn bắt nguồn từ Cọc Sáu, Quảng Lợi chảy vào sông Mông Dương. Hai suối này thường có nước quanh năm, lưu lượng nước thay đổi từ: $1 \div 10 \mathrm{l} / \mathrm{s}$ (mùa khô) đến $100 \mathrm{l} / \mathrm{s}$ vào mùa mưa (Phạm Đại Hải, Đỗ Kiên Cường, Trần Văn Yết 2004). Sông Mông Dương bắt nguồn từ Khe Chàm chảy ra biển, lòng sông rộng $40 \div 50 \mathrm{~m}$. Mức nước sông lên cao nhất +6,7 m (các năm 1979, 1986, 2018 gây ngập lụt mỏ), thấp nhất là +0,4 m (vào mùa khô).

Mỏ than Mông Dương thuộc cánh bắc của nếp uốn bối tà lớn có phương trùng với kinh tuyến. Trên nếp bối tà này có 12 nếp uốn nhỏ và các phay đứt gãy, làm cho nếp uốn trở nên phức tạp. Khu mỏ bị phân chia bởi hai phay lớn là $A-A$ và $H-H$. Ảnh hưởng của các đứt gãy kiến tạo rất phức tạp, thường thay đổi theo diện tích và chiều sâu. Các đứt gãy làm đảo lộn cấu trúc địa chất, chia cắt địa tầng thành các khối có cấu tạo khác nhau và đóng vai trò là đới dẫn nước, thoát khí và dễ gây ra biến dạng nguy hiểm. Tính chất cơ lý các loại đá trong đới phá hủy và vùng lân cận đứt gãy, vùng trục uốn nếp bị giảm yếu rõ rệt.

Điều kiện địa chất thuỷ văn rất phức tạp, mạng lưới sông suối chảy theo các khe núi, thung lũng dốc và đổ dồn về suối Vũ Môn và sông Mông Dương. Hệ số thấm $K$ của đất đá trung bình khoảng $0,001 \div 0,3$ m/ngày đêm (ngđ). Độ kiên cố đất đá mỏ Mông Dương theo thang phân loại của GS. Protodiakonov được đánh giá từ trung bình đến cứng, với $\mathrm{f}=3 \div 10$. Kết quả nghiên cứu cho thấy, tính chất cơ lý đá thay đổi không theo qui luật (VNIMI, 1998). Trong các lớp đá, đặc biệt là các đá hạt thô thường tồn tại $3 \div 4$ hệ kẽ nứt nguyên sinh. Các đứt gãy trung bình, theo qui ước chung được chọn làm ranh giới giữa các khu khai thác.

Hệ thống khai thác cột dài theo phương, khấu than bằng khoan - nổ mìn, chống lò chợ bằng cột thuỷ lực đơn hoặc giá thuỷ lực di động được áp dụng chủ yếu cho khu vực vỉa dốc thoải. Các hệ thống này mang lại các chỉ tiêu kinh tế kỹ thuật cao, nhưng cũng gây biến dạng lớn bề mặt mỏ do điều khiển đá vách bằng phá hoả toàn phần. Hệ thống khai thác gương lò ngắn bao gồm các hệ thống khai thác lò dọc vỉa phân tầng, buồng - thượng, buồng lò chợ được áp dụng cho khu vực vỉa dốc. Do độ sâu khai thác hiện nay của mỏ mói ở mức -150 m, hơn nữa mỏ lại nằm ở vùng đồi núi, khá xa khu dân cư nên chưa chú ý đúng mức đến việc kiểm soát quá trình dịch chuyển đất đá. Đây chính là sự tiềm ẩn 
thảm hoạ bục nước vào lò mà hậu quả không thể lường trước.

\section{Các phương pháp tính toán độ sâu khai thác an toàn cho tập vỉa trong điều kiện địa chất đặc biệt}

Độ sâu khai thác an toàn dưới tất cả các đối tượng chứa nước, trừ tầng đất đá chứa nước có thế nằm chỉnh hợp với vỉa than, được tính từ biên giới dưới của đối tượng chứa nước theo phương thẳng đứng. Độ sâu khai thác an toàn tầng đất đá chứa nước có thế nằm chỉnh hợp với vỉa than tính từ trụ tầng chứa nước theo phương vuông góc với mặt vỉa than (VNIMI, 1998).

Độ sâu khai thác an toàn khi khai thác một vỉa than độc lập dưới đối tượng chứa nước trong trường hợp địa tầng không có phá hủy kiến tạo hoặc có mặt phẳng trục của uốn nếp được xác định như sau:

a. Đối với đối tượng chứa nước nhóm I khi chiều dày lớp sét (á sét) $15 \mathrm{~m}>\mathrm{Gk}>2 \mathrm{~m}$ và chiều dày vỉa than $m \leq 2 \mathrm{~m}$ thì:

$$
H_{a}=0,7 \frac{m}{\varepsilon_{k_{i}}}
$$

Trong đó: $\mathrm{m}$ - chiều dày khai thác của vỉa than; khi khai thác chèn lấp lò thì $m$ là chiều dày quy đổi của vỉa than; $\varepsilon_{\mathrm{ki}}$ - chỉ số biến dạng kéo ở đất đá nền của đối tượng chứa nước nhóm I tại độ sâu khai thác an toàn khi khai thác một vỉa than độc lập:

$$
\varepsilon_{K_{1}}=1,45 \cdot 10^{-3} \cdot\left(G_{K} / 1 m\right)+13 \cdot 10^{-3}
$$

Trong đó: $\mathrm{G}_{\mathrm{k}}$ - chiều dày lớp sét (á sét), m; khi $\mathrm{G}_{\mathrm{k}}>15 \mathrm{~m}$, độ sâu khai thác an toàn xác định như khi $\mathrm{G}_{\mathrm{k}}=15 \mathrm{~m}$, tuy nhiên nó có thể giảm xuống trên cơ sở xác định thực tế chiều cao vùng nứt nẻ dẫn nước.

Khi chiều dày khai thác vỉa than $m>2 \mathrm{~m}$ và chiều dày lớp sét (á sét) $\mathrm{G}_{\mathrm{k}}>10 \mathrm{~m}$, nhưng không nhỏ hơn 2 m, độ sâu khai thác an toàn dưới đối tượng chứa nước nhóm I xác định theo công thức (VNIMI, 1998):

$$
H_{a}=20 \mathrm{~m}
$$

Khi chiều dày khai thác vỉa than $m>2 \mathrm{~m}$ và chiều dày lớp sét (á sét) $\mathrm{G}_{\mathrm{k}}<10 \mathrm{~m}$, cũng như trong trường hợp địa tầng khoáng sàng cấu tạo bởi các lớp sét dẻo, dễ trương nở, độ sâu khai thác an toàn vỉa than dưới đối tượng chứa nước xác định trên cơ sở xác định thực tế chiều cao vùng nứt nẻ dẫn nước.

b. Đối với đối tượng chứa nước nhóm II khi chiều dày lớp sét (á sét) $\mathrm{G}_{\mathrm{k}}<2 \mathrm{~m}$ và $\mathrm{m}<2 \mathrm{~m}$, độ sâu an toàn được xác định theo công thức:

$$
H_{a}=0,7 \frac{m}{\varepsilon_{K_{2}}}
$$

Trong đó: $\varepsilon_{\mathrm{k} 2}$ - chỉ số biến dạng kéo ở đất đá nền của đối tượng chứa nước nhóm II tại độ sâu khai thác an toàn khi khai thác một vỉa than độc lập.

$$
\varepsilon_{K_{2}}=6,4 \cdot 10^{-3} K_{S}+11,1 \cdot 10^{-3}
$$

Trong đó: $K_{s}=M_{a} / M$ - tỉ số tổng chiều dày các lớp sét kết, bột kết, sét phiến $\mathrm{M}_{\mathrm{a}}$ trên chiều dày $\mathrm{M}$ địa tầng nằm trên khu vực khai thác tính từ đường bao dưới đối tượng chứa nước đến biên giới trên vùng sập lở và nứt nẻ lớn ở vách vỉa than; chiều cao vùng sập lở và nứt nẻ lớn tính bằng $\mathrm{h}_{0}=10 \mathrm{~m}$.

Trong trường hợp khai thác tập vỉa than dưới đối tượng chứa nước theo trình tự kế tiếp nhau, từ vỉa trên xuống vỉa dưới, cho phép tiến hành sau khi kết thúc thời kì biến dạng nguy hiểm ở vỉa đã khai thác nằm trên.

Trong trường hợp này, tập vỉa được phân chia thành các nhóm cùng được khai thác (vỉa cùng khai thác được hiểu là các vỉa mà các đường lò tạo ra cùng loại biến dạng).

Nếu nhóm vỉa trong vùng ảnh hưởng khai thác có nhiều hơn 3 vỉa, thì độ sâu khai thác an toàn được xác định theo 3 vỉa có ảnh hưởng nhất. Việc khai thác các vỉa kế tiếp trong nhóm được tiến hành thiết kế riêng.

Khi cùng khai thác tập vỉa than theo trình tự từ trên xuống, độ sâu khai thác an toàn $\mathrm{H}_{\mathrm{a}(1+2+3)}$ xác định theo điều kiện sau (Hình 1a) (VNIMI, 1998):

$$
\begin{aligned}
\frac{m_{1}}{H_{a(1+2+3)}} & +\frac{m_{2}}{H_{a(1+2+3)}+h_{1-2}} \\
& +\frac{m_{3}}{H_{a(1+2+3)}+h_{1-3}} \\
& \leq \frac{m_{1}}{H_{a_{1}}}
\end{aligned}
$$

Trong đó: $\mathrm{m}_{1}, \mathrm{~m}_{2}, \mathrm{~m}_{3}$ - chiều dày khai thác tương ứng các vỉa than $1,2,3$ có ảnh hưởng nhất (là các vỉa than có tỉ lệ giữa chiều dày vỉa với độ sâu trung bình dưới đối tượng chứa nước lớn nhất); $\mathrm{h}_{1}$ -2, $\mathrm{h}_{2-3}$ - khoảng cách pháp tuyến giữa các vỉa than (khoảng cách trực giao đến mặt vỉa than) tương úng giữa trụ vỉa than thứ nhất (trên cùng) và vách vỉa than thứ hai và thứ ba; $H_{a_{1}}$ - độ sâu khai thác an toàn một vỉa than trên cùng, xác định theo các công thức $(3,4,5)$ tương ứng điều kiện nhóm vỉa; 
a

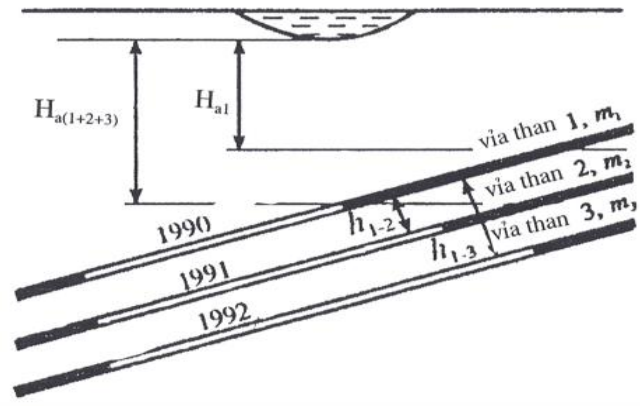

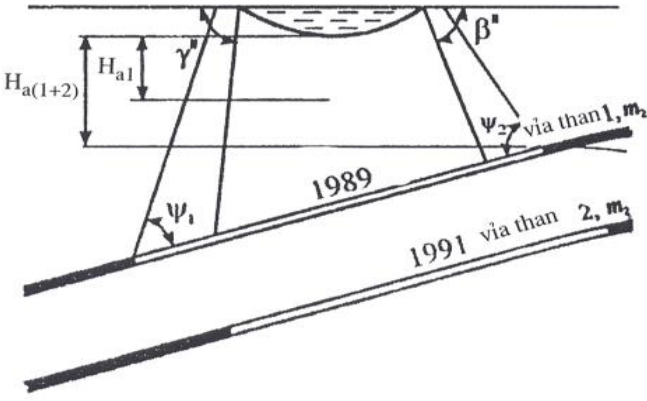

Hình 1. Sơ đồ xác định độ sâu khai thác an toàn tập vỉa than.

$a$ - khi cùng khai thác tập vỉa than; $b$ - khi khai thác nối tiếp nhau.

$\mathrm{H}_{\mathrm{a}(1+2+3)}$ - độ sâu khai thác an toàn của 3 vỉa than ảnh hưởng nhất.

Độ sâu khai thác an toàn cho hai vỉa than cùng khai thác $\mathrm{H}_{\mathrm{a}(1+2)}$ được xác định theo công thức (VNIMI, 1998):

$$
\begin{gathered}
\frac{m_{1}}{H_{a(1+2)}}+\frac{m_{2}}{H_{a(1+2)}+h_{1-2}}=\frac{m_{1}}{H_{a_{1}}} \\
H_{a_{(1+2)}}=\frac{H_{a_{1}}\left(1+\frac{m_{2}}{m_{1}}\right)-h_{1-2}}{2} \\
+\frac{\sqrt{\left[H_{a_{1}}\left(1+\frac{m_{2}}{m_{1}}\right)-h_{1-2}\right]^{2}+4 H_{a_{1}} h_{1-2}}}{2}
\end{gathered}
$$

Nếu trong vùng ảnh hưởng của đối tượng chứa nước, tập vỉa than được khai thác kế tiếp nhau mà không để lại trụ than bảo vệ và lò chợ được khai thác với khoảng gián đoạn thời gian lớn hơn tổng thời gian dịch chuyển, tức là vùng dịch chuyển của vỉa than khai thác tiếp theo phía dưới rơi vào phạm vi trụ than cho đối tượng chứa nước trong vùng dịch chuyển toàn phần của vỉa than khai thác trước (Hình $1 b$ ), thì độ sâu khai thác an toàn cho 2 vỉa than tiếp theo được xác định theo trình tự sau:

a. Theo các công thức $(3,4,5)$ xác định độ sâu an toàn cho từng vỉa than khai thác độc lập;

b. Xác định độ sâu an toàn cho khai thác 2 vỉa than như sau:

$$
\begin{aligned}
& H_{a_{(1+2)}} \\
& =\frac{H_{a_{1}}\left(k_{1}+\frac{m_{2}}{m_{1}}\right)-h_{1-2}}{2} \\
& +\frac{\sqrt{\left[H_{a_{1}}\left(k_{1}+\frac{m_{2}}{m_{1}}\right)-h_{1-2}\right]^{2}+4 H_{a_{1}} k_{1}}}{2}
\end{aligned}
$$

Trong đó: $\mathrm{k}_{1}$ - hệ số thể hiện biến dạng còn dư của đất đá trong mặt phẳng đáy bồn dịch chuyển do ảnh hưởng của khai thác vỉa than trên và được xác định theo Bảng 1.

Bảng 1. Giá trị hệ số $k_{1}, k_{2}$.

\begin{tabular}{|c|c|c|}
\hline TT & Khoáng sàng & $\mathrm{k}_{1}, \mathrm{k}_{2}$ \\
\hline 1 & Kuzbass (Liên Xô cũ) & 0,35 \\
\hline 2 & Các vùng khác & $0,35 \div 0,45$ \\
\hline
\end{tabular}

\section{Xác định vùng ảnh hưởng nguy hiểm và độ sâu khai thác an toàn khi khai thác tập vỉa}

\subsection{Mặt cắt đặc trung vuông góc vơi suối, trên cở sở các góc $\beta^{\prime \prime}, \gamma^{\prime \prime}$}

Vùng ảnh hưởng nguy hiểm có nguy cơ bục nước vào các đường lò là khu vực vỉa nằm trong giới hạn được xác định bởi giao điểm của vỉa với các góc $\beta^{\prime \prime}, \gamma^{\prime \prime}$ dựng từ mặt địa hình lấy từ đai an toàn của suối thể hiện trên các Hình 2 và 3 .

Trên cơ sở phương pháp tính toán, xác định chiều sâu khai thác an toàn dưới đối tượng chứa nước và nghiên cứu tài liệu địa chất của mỏ than Mông Dương. Địa tầng đáy sông, suối có lớp sét chiều dày $\mathrm{G}_{\mathrm{k}}=2 \mathrm{~m}$.

\subsection{Tính toán xác định chiều sâu khai thác an toàn cho tập vỉa}

Dưới suối có tập vỉa than gồm 3 vỉa: $\mathrm{V7}, \mathrm{V6}$, V5 khai thác theo trình tự từ trên xuống dưới, có góc dốc $\alpha=12^{0}$, chiều dày tương ứng là $\mathrm{m}_{1}=3,4 \mathrm{~m} ; \mathrm{m}_{2}$ $=3,6 \mathrm{~m} ; \mathrm{m}_{3}=5 \mathrm{~m}$. Chiều dày đất đá giữa các vỉa than $V_{7}$ và $V_{6}$ là $h_{7-6}=20 \mathrm{~m}, V_{7}$ và $V_{5}$ là $h_{7-5}=58 \mathrm{~m}$.

Sông Mông Dương thuộc nhóm đối tượng chứa nước II có $G_{k}<2 m$ và $2 m<m \leq 4 m$ độ sâu 


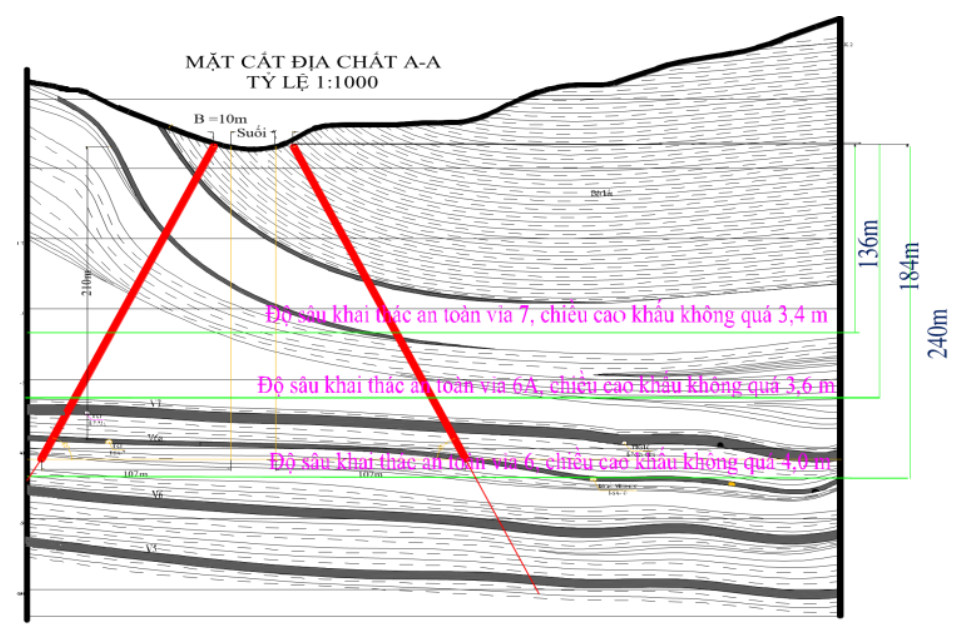

Hình 2. Độ sâu khai thác an toàn cho vỉa 7, 6, 5 theo mặt cắt $A$ - A.

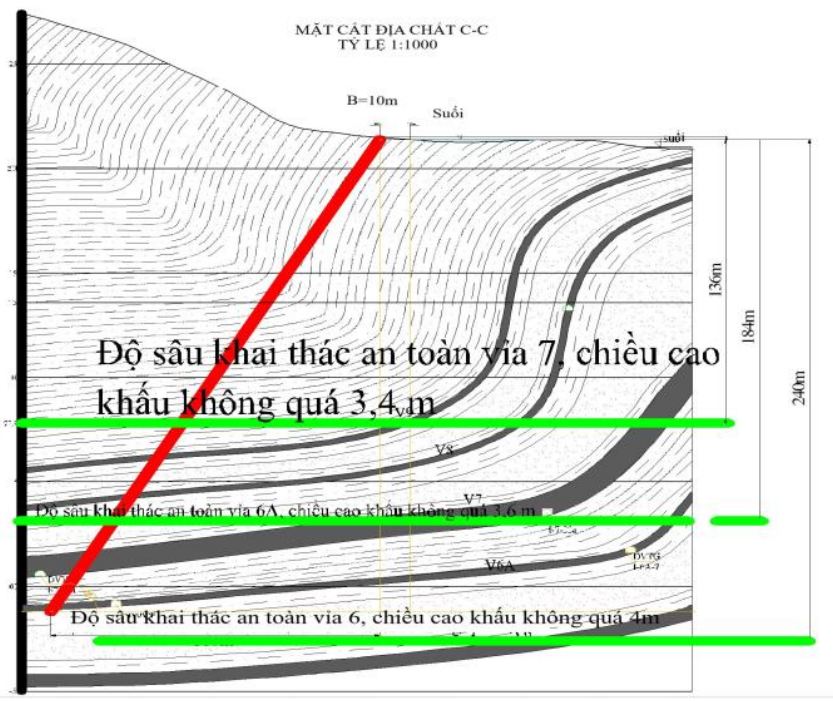

Hình 3. Độ sâu khai thác an toàn cho vỉa 7, 6, 5 theo mặt cắt $C$ - $C$.

khai thác an toàn tính bằng:

$$
H_{a}=40 m, k h i \frac{M_{a}}{M} \geq 0,4
$$

Trong đó: Ma - tổng chiều dày của các lớp bột kết, sét kết và sét than; $\mathrm{M}$ - chiều dày cột địa tầng nằm dưới các đối tượng chứa nước không có đứt gẫy kiến tạo, chiều dày lớp sét $\leq 2 \mathrm{~m}$ và thỏa mãn điều kiện sau:

$$
G_{K}<1,5(3,4+3,6+5)=22.5
$$

Do đó, độ sâu khai thác an toàn dưới suối tính lần lượt cho các vỉa như sau:

Đối với vỉa 7

$$
H_{7}=40 \mathrm{~m}=40 \times 3.4=136 \mathrm{~m}
$$

Trong trường hợp khai thác tập vỉa dưới đối

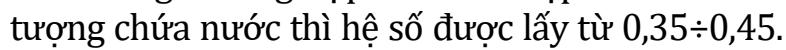

Do vậy, nghiên cứu này đã lấy hai trường hợp tính toán với $\mathrm{k}_{1}=0,4$ và 0,45 .

Khi khai thác vỉa 6 có độ sâu khai thác an toàn được tính theo công thức:

$$
\begin{aligned}
& H_{7+6}\left(k_{1}+\frac{m_{6}}{m_{7}}\right)-h_{7-6} \\
& 2 \\
& +\frac{\sqrt{\left[H_{7}\left(k_{1}+\frac{m_{6}}{m_{7}}\right)-h_{7-6}\right]^{2}+4 H_{7} k_{1} h_{7-6}}}{2}
\end{aligned}
$$

Với $\mathrm{k}_{1}=0,4$

$$
\begin{gathered}
H_{7+6}=\frac{136\left(0,45+\frac{3,6}{3,4}\right)-20}{2}+ \\
+\frac{\sqrt{\left[136\left(0,45+\frac{3,6}{3,4}\right)-20\right]^{2}+4.136 .0,45.20}}{2}=192(\mathrm{~m})
\end{gathered}
$$


Để đảm bảo an toàn trong quá trình khai thác đối với vỉa 6 , kiến nghị lấy $\mathrm{k}_{1}=0,45$, chiều sâu khai thác an toàn $\mathrm{H}_{7+6}=192 \mathrm{~m}$.

Khi khai thác tiếp đến vỉa 6, chiều sâu khai thác an toàn áp dụng công thức:

$$
\begin{gathered}
\frac{k_{1} \cdot m_{7}}{H_{7+6+5}}+\frac{k_{2} \cdot m_{6}}{H_{7+6+5}+h_{7-6}}+\frac{m_{5}}{H_{7+6+5}+h_{7-5}} \\
\leq \frac{m_{7}}{H_{7}}
\end{gathered}
$$

$\mathrm{H}_{7+6+5}$ - độ sâu khai thác an toàn đối với vỉa 6; $\mathrm{m}_{7 / \mathrm{H} 7}=1 / 40$,

Thay các giá trị của chiều cao khấu và độ sâu khai thác an toàn của các vỉa 7 và 6 ta có biểu thức:

$$
\begin{aligned}
& \frac{0.45 \times 3.4}{H_{7+6+5}}+\frac{0.45 \times 3.6}{H_{7+6+5}+20}+\frac{m_{5}}{H_{7+6+5}+58} \leq \frac{3,4}{136} \\
& \frac{1.53}{H_{7+6+5}}+\frac{1.62}{H_{7+6+5}+20}+\frac{m_{5}}{H_{7+6+5}+58} \leq 0,025
\end{aligned}
$$

Do vậy cần phải chọn chiều dày vỉa 6 là $\mathrm{m}_{6}$ và chiều sâu khai thác an toàn $\mathrm{H}_{5}$ vỉa 5 để thỏa mãn biểu thức trên.

Trên mặt cắt địa hình khoảng cách nhỏ nhất từ đáy suối đến vỉa 5 trong vùng có nguy cơ ảnh hưởng bục nước là $240 \mathrm{~m}$. Bằng cách thay đổi chiều cao khấu của vỉa 6 từ $3 \div 4 \mathrm{~m}$, xác định được khi $\mathrm{H}_{7+6+5}=240 \mathrm{~m}$ và $\mathrm{m}_{5}=4 \mathrm{~m}$ thỏa mãn điều kiện trên:

$$
\frac{1,53}{240}+\frac{1,62}{240+20}+\frac{4}{240+58}=0,025
$$

Vậy vỉa 5 khai thác với chiều khấu nhỏ hơn 4 $m$ thì độ sâu khai thác an toàn là $240 \mathrm{~m}$.

Các giá trị góc nứt tách cho trước tại:

- Via 7:

$$
\begin{gathered}
\delta_{1}^{\prime \prime}=\delta-\Delta \delta_{c}+10=80-5+10=85^{0} \\
\delta_{1}^{\prime \prime}=\beta-\Delta \beta_{c}+10=(82-\alpha)-5+10=75^{0} \\
\gamma_{1}^{\prime \prime}=\gamma-\Delta \gamma_{c}+10=80-5+10=85^{0}
\end{gathered}
$$

- Via 6:

$$
\begin{aligned}
& \delta_{2}^{\prime \prime}=\delta_{1}^{\prime \prime}+\Delta \delta_{c}=85+3=88^{0} \\
& \beta_{2}^{\prime \prime}=\beta_{1}^{\prime \prime}+\Delta \beta_{c}=75+3=78^{0} \\
& \gamma_{2}^{\prime \prime}=\gamma^{\prime \prime}+\Delta \gamma_{c}=85+3=88^{0}
\end{aligned}
$$

- Via 5:

$$
\begin{aligned}
& \delta_{3}^{\prime \prime}=\delta_{1}^{\prime \prime}+\Delta \delta_{c}=85+5=90^{0} \\
& \beta_{3}^{\prime \prime}=\beta_{1}^{\prime \prime}+\Delta \beta_{c}=75+5=80^{0} \\
& \gamma_{3}^{\prime I}=\gamma_{1}^{\prime \prime}+\Delta \gamma_{c}=85+5=90^{\circ}
\end{aligned}
$$

\section{Kết luận}

Kết quả nghiên cứu cho thấy, mỏ than Mông Dương có điều kiện địa chất phức tạp, đặc biệt do có địa hình bị chia cắt, có nhiều đối tượng chứa nước; trong địa tầng có nhiều đứt gãy, uốn nếp và có chứa nhiều vỉa than với góc dốc thay đổi.

Việc xác định độ sâu an toàn khi khai thác tập vỉa dưới các đối tượng chứa nước ở mỏ than Mông Dương theo phương pháp của viện VNIMI là hợp lý và tin cậy. Kết quả nghiên cứu đã xác định được độ sâu an toàn $\mathrm{H}_{5}=240 \mathrm{~m}, \mathrm{H}_{6}=192 \mathrm{~m}, \mathrm{H}_{7}=136 \mathrm{~m}$ khi khai thác 3 vỉa dưới các đối tượng chứa nước; xác định các đại lượng dịch chuyển và biến dạng $\delta_{1,2,3}=$ $80^{\circ}, 88^{0}, 90^{\circ}, \beta_{1,2,3}=75^{0}, 78^{0}, 80^{\circ}, \gamma_{1,2,3}=85^{0}, 88^{0}, 90^{\circ}$ khi khai thác hầm lò ở những vùng có đứt gãy, uốn nếp nhằm dự báo khả năng khai thác dưới an toàn và bảo vệ tốt nhất các công trình nằm trong những vùng nguy hiểm.

Chiều sâu khai thác an toàn phụ thuộc vào nhiều yếu tố, trong đó có yếu tố công nghệ khai thác, điều kiện địa chất, khai thác càng sâu so với mặt đất thì an toàn cho công trình dân dụng công nghiệp càng tăng.

\section{Lời cảm ơn}

Nghiên cứu này được tài trợ bởi đề tài cấp cơ sở, mã số T19 - 45 của Trường Đại học Mỏ - Địa chất.

\section{Đóng góp của các tác giả}

Phạm Văn Chung, Phùng Mạnh Đắc - hình thành ý tưởng và nội dung bài báo, triển khai các nội dung, hoàn thành bản thảo cuối của bài báo; Lê Thị Thu Hà, Nguyễn Gia Trọng, Ngô Thành Trung, Trần Vũ Thăng - thu thập số liệu, đọc bản thảo trung gian.

\section{Tài liệu tham khảo}

Ambrožič Tomaž, Turk Goran, (2003), "Prediction of subsidence due to underground mining by artificial neural networks, Computers \& Geosciences, 29 (5), 627 - 637. 
Agnieszka Malinowska, Ryszard Hejmanowski, Hua - yang Dai. (2020), Ground movements modeling applying adjusted influence function. International Journal of Mining Science and Technology, 30(1).

Alex Hay - Man Ng., Linlin Ge, Du Zheyuan, Wang, Shuren, \& Ma Chao. (2017). Satellite radar interferometry for monitoring subsidence induced by longwall mining activity using Radarsat - 2, Sentinel - 1 and ALOS - 2 data. International Journal of Applied Earth Observations and Geoinformation, 61, 92 - 103. doi:10.1016/j.jag.2017.05.009.

Nguyen Quoc Long, Xuan - Nam Bui, Luyen Khac Bui, Khoa Dat Vu Huynh, Canh Van Le, Michał Buczek, Thang Phi Nguyen. (2017). A Computational Tool for Time Series Prediction of Mining - Induced Subsidence Based on Time Effect Function and Geodetic Monitoring Data. In International Conference on Geo - Spatial Technologies and Earth Resources. 2017. Springer, 1 - 16, DOI: 10.1007/978 - 3 - 319 68240 - 2_1.

Nguyen Quoc Long, Adeel Ahmad, Cao Xuan Cuong Cao, Le Van Canh. (2018). Designing observation lines: a case study of the G9 seam in the Mong Duong colliery, Journal of Mining and Earth Sciences, 60(3). 18 - 24.

Nguyễn Quoc Long. (2020). Đanh gia kha năng ung dụng ham măt cắt trong dự báo lún do khai thac hầm lò tại Việt Nam, Công nghiệp mỏ, 3, 93 - 99.

Nguyễn Tam Sơn, Phạm Văn Chung. (2005). Báo cáo kết quả quan trắc trên bề mặt địa hình vỉa I (12) mỏ than Mông Dương. Viện Khoa học Công nghệ Mỏ.

Phạm Đại Hai, Đỗ Kien Cương, Trần Văn Yet. (2004). Kết quả thí nghiệm tính chất cơ lý đá. Viện Khoa học Công nghệ Mỏ.
Pham Văn Chung, Vương Trong Kha. (2012). Xác định các thông số dịch chuyển và biến dạng đất đá do ảnh hưởng của khai thác hầm lò mỏ than Mông Dương. Tuyển tập báo cáo Hội nghị khoa học kỹ thuật mỏ toàn quốc lần thứ XXIII, 130 140.

Pham Van Chung, Cuong Cao Cuong, Nguyen Quoc Long. (2019). An initial assessment of the impact of coal mining on the Khe Cham washing plant (Vietnam), International Journal of Scientific and Engineering Research, 10(4): 914 - 922.

Ryszard Hejmanowski, Agnieszka A. Malinowska, Wojciech T. Witkowski, Artur Guzy. (2019). An Analysis Applying InSAR of Subsidence Caused by Nearby Mining - Induced Earthquakes. Geosciences, 9(12), 490.

VNIMI. (1998). Quy phạm bảo vệ công trình và các đối tượng tự nhiên tù̀ ảnh hương có hại khi khai thác hầm lò dưới khoáng sàng than. Sait Peterburg.

Vardoulakis I., Graf B., Gudehus G. (1981), Trapdoor problem with dry sand: A statical approach based upon model test kinematics, International Journal for Numerical and Analytical Methods in Geomechanics, 5(1), 57 78.

Xiaoping, Z., Jian, Z., \& Wenlong, L. (2016). 3D laser scanning technology in the application of modeling in mining subsidence area. Paper presented at the 2016 5th International Conference on Civil, Architectural and Hydraulic Engineering (ICCAHE 2016).

Zhang, Z., Wang, C., Tang, Y., Zhang, H., \& Fu, Q., (2015). Analysis of ground subsidence at a coal - mining area in Huainan using time - series InSAR. International Journal of Remote Sensing, 36(23), 5790 - 5810. doi:10.1080/014 31161. 2015.1109725 . 